\section{Internet addiction: a case report} Dependência de internet: um relato de caso

Internet addiction (IA) is the lack of ability to control Internet use and involvement leading to progressive loss of control. With negative social effects, Internet addicts use the Web as a social and communication tool, once they experience higher levels of pleasure and satisfaction when online than in real life ${ }^{1}$.

We report the case of F., 15, from Sao Paulo, an only child who had been confined at home for 2 years for being online (average, 12-18 hrs/day, maximum, 38 hrs uninterruptedly). In addition to excessively worrying about the Internet (Criterion \#1), he also showed a constant need for increasing online time (Criterion \#2) and eventually lost control over use (Criterion \# 3). With his parents split, he stopped going to school for 2 years (Criterion \#6) and would not leave his room, where he got online. The Internet gave him relief by providing an escape from his life problems (Criterion \#8). Irritated when his mother unplugged the computer (Criterion \# 4), he physically attacked her three times. In the past, showing depression, he was hospitalized due to his aggressiveness after oral administration of fluoxetine.
Brought in for refusing treatment, he showed dysphoric mood, grandiose ideation, logorrhea, compromised pragmatism, and no critical sense about his condition.

By applying CY-BOCS, concerns about contamination, excessive hand washing, ritualized toilet, nose-cleaning compulsion, and clothing checking (consuming 2 hours a day) were revealed, although there was no critical sense about them.

During hospitalization, bipolar disorder (BD), attention-deficit/ hyperactivity disorder (ADHD) with predominance of inattentiveness, obsessive-compulsive symptoms, simple phobia, and impulse control disorder, NOS (IA) were hypothesized. He had previous family history of alcohol and drug abuse, BD, and depression.

F. was discharged after 14 days, showing mood stabilization with divalproate sodium $750 \mathrm{mg} /$ day and partial critical sense about his problem. Outpatient treatment was indicated. We cannot report the progression of Internet use-related behavior following hospitalization because the patient dropped out treatment.

Many adolescents are difficult to treat and highly resistant to treatment, once the Internet is disseminated in this age group as a habit incorporated to school life and social relationships (e.g., Orkut). The Web has become an anonymity and comfort zone, where the delay in communication favors the creation of better forms of self-expression, such as the possibility of creating new personal characteristics. Thus, for individuals having social anxiety or low self-esteem the perspective of manipulating reality turns the

Table 1 - Internet addiction. Diagnostic criteria by Young ${ }^{2}$

Respondents who answered "yes" to five or more of the criteria were classified as addicted (Dependents)

1. Do you feel preoccupied with the Internet (think about previous online activity or anticipate next online session)?

2. Do you feel the need to use the Internet with increasing amounts of time in order to achieve satisfaction?

3. Have you repeatedly made unsuccessful efforts to control, cut back, or stop Internet use?

4. Do you feel restless, moody, depressed, or irritable when attempting to cut down or stop Internet use?

5. Do you stay online longer than originally intended?

6. Have you jeopardized or risked the loss of significant relationship, job, educational or career opportunity because of the Internet?

7. Have you lied to family members, therapist, or others to conceal the extent of involvement with the Internet?

8. Do you use the Internet as a way of escaping from problems or of relieving a dysphoric mood (e.g., feelings of helplessness, guilt, anxiety, depression)? 
cyberspace into a new window to the world, offering comfort and relief. Those showing distractibility or accelerated thinking, in turn, may find encouragement in the Internet that allows them to focus their attention more accordingly to the speed of their ideas. ${ }^{1}$

Several studies indicate an association of IA with other psychiatric disorders that, when present as comorbidities, predisposes, aggravates, or facilitates excessive Internet use, thereby hampering the identification and approach of the problem. The failure in recognizing it may negatively affect prognosis. ${ }^{2-4}$
This patient's history shows the disorder had been long standing, although it was never correctly diagnosed, which led to major social impacts for not receiving appropriate treatment.

Andréas Stravogiannis, Cristiano Nabuco de Abreu Ambulatório Integrado dos Transtornos do Impulso (AMITI), Institute of Psychiatry, School of Medicine, Universidade de São Paulo (USP), São Paulo (SP), Brazil

\begin{tabular}{|c|c|c|c|c|c|c|c|}
\hline $\begin{array}{l}\text { Writing group } \\
\text { member }\end{array}$ & Employment & $\begin{array}{l}\text { Research } \\
\text { grant }^{1}\end{array}$ & $\begin{array}{l}\text { Other } \\
\text { research } \\
\text { grant or } \\
\text { medical } \\
\text { continuous } \\
\text { education } \\
\end{array}$ & $\begin{array}{l}\text { Speaker's } \\
\text { honoraria }\end{array}$ & $\begin{array}{l}\text { Ownership } \\
\text { interest }\end{array}$ & $\begin{array}{l}\text { Consultant/Ad } \\
\text { visory board }\end{array}$ & Other $^{3}$ \\
\hline $\begin{array}{l}\text { Andréas } \\
\text { Stravogiannis }\end{array}$ & AMITI & --- & --- & --- & --- & --- & FUAA \\
\hline $\begin{array}{l}\text { Cristiano Nabuco } \\
\text { de Abreu }\end{array}$ & AMITI & --- & -- & --- & --- & --- & --- \\
\hline
\end{tabular}

${ }^{*}$ Modest

** Significant

*** Significant. Amounts given to the author's institution or to a colleague for research in which the author has participation, not directly to the author.

Note: $A M I T I=$ Ambulatório Integrado dos Transtornos do Impulso do Instituto de Psiquiatria da Universidade de São Paulo; FUAA = Fundo de Aprimoramento Acadêmico do Departamento de Psiquiatria da Faculdade de Medicina da Universidade de São Paulo.

For more information, see Instructions for authors.

\section{References}

1. Abreu CN, Karam RG, Góes DS, Spritzer DT. Internet and videogame addiction: a review. Rev Bras Psiquiatr. 2008;30(2):156-67.

2. Young K. Internet Addiction: the emergence of a new clinical disorder. Cyberpsychol Behav. 1988;1(3)237-44.

3. Shapira NA, Lessig MC, Goldsmith TD, Szabo ST, Lazoritz M, Gold MS, Stein, DJ. Problematic Internet Use: proposed classification and diagnostic criteria. Depress Anxiety. 2003;17(4):207-16.

4. Cao F, Su L. Internet addiction among Chinese adolescents: prevalence and psychological features. Child Care Health Dev. 2007,33(3):275-81. 